\title{
André Pratte, Aux pays des merveilles. Essai sur les mythes politiques québécois
}

\section{Simona Rossi}

\section{Q OpenEdition}

1 Journals

\section{Edizione digitale}

URL: https://journals.openedition.org/studifrancesi/46390

DOI: 10.4000/studifrancesi.46390

ISSN: 2421-5856

\section{Editore}

Rosenberg \& Sellier

\section{Edizione cartacea}

Data di pubblicazione: 1 octobre 2007

Paginazione: $487-488$

ISSN: 0039-2944

\section{Notizia bibliografica digitale}

Simona Rossi, «André Pratte, Aux pays des merveilles. Essai sur les mythes politiques québécois», Studi Francesi [Online], 152 (LI | II) | 2007, online dal 30 novembre 2015, consultato il 24 novembre 2021. URL: http://journals.openedition.org/studifrancesi/46390 ; DOI: https://doi.org/10.4000/studifrancesi. 46390

Questo documento è stato generato automaticamente il 24 novembre 2021.

\section{(c) $($ ) $\odot$}

Studi Francesi è distribuita con Licenza Creative Commons Attribuzione - Non commerciale - Non opere derivate 4.0 Internazionale. 


\title{
André Pratte, Aux pays des merveilles. Essai sur les mythes politiques québécois
}

\author{
Simona Rossi
}

\section{NOTIZIA}

ANDRÉ PRATTE, Aux pays des merveilles. Essai sur les mythes politiques québécois, Montréal, VLB Éditeur, 2006, pp. 153.

1 André Pratte, giornalista e grande appassionato di politica, espone in questo testo critico una teoria davvero interessante: secondo la sua opinione i quebecchesi non si trovano per nulla in bilico tra due differenti e opposte tendenze politiche, ossia la sovranità e il federalismo, ma sono piuttosto "succubi" di tutti quei miti che nel corso del tempo uomini politici e intellettuali hanno creato a tavolino per loro. La collettività quebecchese esita dunque attualmente nel riconoscersi in questa o quell'idea di paese: una tratteggia un paese ideale, che dovrebbe sorgere come per magia dal fuoco e dalle ceneri dell'indipendenza; un'altra esalta un paese idilliaco e perfetto, senza macchia e senza paura, figlio stoico ed eroico di un passato fatto di battaglie "stellari" che l'hanno violentato e messo in ginocchio, non permettendogli di esprimersi completamente in tutte le sue peculiarità; altre ancora si concentrano sul malessere che sembra serpeggiare nel Québec odierno, insoddisfatto e incapace di serenità per colpa della storia, della Francia, degli Inglesi, etc. Tutte idee false e forzate, secondo Pratte, che non fanno altro che aumentare il senso di confusione ed insicurezza dei quebecchesi.

2 L'autore divide la sua opera in quattro parti: le pays martyr, le pays des merveilles, le meilleur pays au monde e le pays réel. Con uno spirito di trasgressione che appare del tutto naturale e spontaneo, Pratte dipana per il lettore la matassa dei più intricati risvolti politici e delle strategie cognitive di cui i potenti del mondo si servono per far presa sui punti deboli dell'immaginario popolare. È soprattutto nell'ultima parte che il tono si fa 
più aspro: egli polemizza sul fatto che gli specchietti per le allodole costituiti da questi miti di paesi immaginari hanno contribuito a oscurare e rendere invisibile l'unico paese che, invece, esiste davvero ed è sempre esistito. Il Canada reale, cioè, con tutti i suoi difetti e le sue debolezze, un paese che potrebbe puntare molto di più sulla sua incredibile forza interiore se solo smettesse di sprecare tempo ed energia cercando di sconfiggere mostri dalle cento teste che di fatto sono del tutto inesistenti, o almeno non così minacciosi come le fazioni politiche vogliono far credere.

cosa desiderano sul serio i quebecchesi odierni? Di cosa esattamente vorrebbero liberarsi? E davvero la lingua e la cultura francese sono talmente in pericolo, in Canada, che più del 40 per cento dei quebecchesi auspica un distacco definitivo del Québec dalla Confederazione? L'autore cerca di rispondere a suo modo a tutti questi quesiti, restando comunque convinto che il nazionalismo potrebbe diventare un sentimento davvero positivo, per i quebecchesi, soltanto nel caso in cui questi ultimi si convincessero che i fantasmi non esistono e che l'unico paese che possono scegliere non è quello martire, meraviglioso, ideale o chissà quale altro, ma soltanto il Québec reale, il solo che abbiano mai posseduto, che si può far crescere e prosperare, indipendentemente dall'eventuale separazione dal resto del Canada.

Certo Pratte non ha la presunzione di avanzare soluzioni definitive alle problematiche tanto complesse che affronta, ma è indubbio che la sua opera schietta e rivoluzionaria apre la via a inedite e intelligenti riflessioni sul mondo politico quebecchese. 